\title{
Characterization of Denture Acrylic Resin Surfaces Modified by Glow Discharges
}

\author{
SSEFIK SÜZER,* NEHIR ÖZDEN, FUNDA AKALTAN, and GÜNERI AKOVALI \\ Department of Chemistry, Bilkent University, 06533 Ankara, Turkey (S.S.); Faculty of Dentistry, Ankara University, 06500 Ankara, \\ Turkey (N.O., F.A.); Department of Chemistry, Middle East Technical University, 06531 Ankara, Turkey (G.A.)
}

\begin{abstract}
Resin samples prepared by compression molding using a poly(methyl methacrylate) (PMMA) denture base material were exposed to radio-frequency ( $r f$ ) glow discharges to improve the wettability of the material. Fourier transform infrared (FT-IR) reflectance, X-ray photoelectron spectroscopy (XPS), and contact-angle measurements have been employed to characterize the changes introduced by the glow discharge plasma. FT-IR measurem ents cannot detect any modification. XPS reveals an increase in the $\mathrm{O} / \mathrm{C}$ atomic ratio. Contact angles of the plasma-treated samples are always lower when compared with untreated ones. The increased $O$ atomic concentration is attributed to formation of - $\mathrm{COH}$ groups on the surface during plasma treatment. The $\mathrm{O} / \mathrm{C}$ atomic ratio decreases upon heating the samples in vacuum to $100{ }^{\circ} \mathrm{C}$ for 1-2 min and exposing the samples to liquid $\mathrm{CH}_{2} \mathrm{Cl}_{2}$ for 1-2 min. Exposure to distilled water for prolonged periods causes a slight decrease during the initial 1-20 days but levels off to a constant value up to a period of 60 days. Plasma treatment seems to offer a durable increase in the wettability for these materials left in air or distilled water.
\end{abstract}

Index Headings: Denture base materials; PMMA; Plasma modification; XPS; Contact angles.

\section{INTRODUCTION}

Poly(methyl methacrylate), PMMA, is the most commonly used material for denture base. Therefore its adhesion to the underlying mucosa is very important and depends on various physicochemical factors. The basic requirement for good adhesion is intimate contact between the adhesive and the adherent. The extent to which an adhesive will wet a surface depends, among other factors, on the contact angle $(\theta)$ at which the adhesive meets the adherent surface. Since the tendency for the liquid to spread increases as $\theta$ decreases, the contact angle is a useful inverse measure of spreadability or wettability. ${ }^{1}$ Kilani et al. measured contact angles between the synthetic saliva and distilled water on a selected number of base materials and reported that the contact angles between saliva and distilled water were statistically comparable for a given denture base material. ${ }^{2}$ The reported contact angle values of water on PMMA varies between 60 and $80^{\circ}$ depending on whether the advancing or receding angle is measured. For the denture base materials that contain PMMA and other additives, the reported contact angle values are also in this range.

Surface modification using various chemical and/or physical methods to improve its adhesion (assumed to be related to wettability) has been reported. ${ }^{3-6}$ Here, again, improvement in the wettability was assessed by lowering the water contact angles after treatment. However, Murray critically questioned the effectiveness of surface treat-

Received 11 November 1996; Accepted 23 May 1997.

* Author to whom correspondence should be sent. ment on PMMA when exposed in the mouth. ${ }^{6}$ He treated the PMMA surface using either (1) aqueous hydroxyl radicals generated by two chemical methods or (2) lowpressure electrical discharge. Using the contact angle measurements, he reported the treatment with aqueous hydroxyl radicals to be totally ineffective and the exposure to a low-pressure electrical discharge in water vapor and air to be initially effective in decreasing the value of the contact angle to near zero. He, however, reported that, with subsequent exposure to water vapor in a humidity chamber or immersion in water, a gradual increase in contact angles was observed, with an eventual return to their original values, and he concluded that there was no prospect for improvement by any surface treatment.

Here, we report Fourier transform infrared (FT-IR), X-ray photoelectron spectroscopy (XPS), and contact-angle study of the denture materials treated by glow-discharge plasma both to characterize the species formed on the surfaces and to assess the durability of such treatments. XPS is a surface-sensitive spectroscopic method and has been very successful in characterizing the physical and chemical changes on the surfaces of plasmatreated polymeric materials. ${ }^{7-11}$ In a recent study Gröning et al. reported an XPS investigation of the chemical modifications of the PMMA surfaces after plasma and lowenergy ion beam treatment. ${ }^{12}$ They found that reactive atomic radicals or ions were responsible for incorporation of extra atoms $(\mathrm{O})$ or groups $(-\mathrm{COO})$ into the polymer surface. Use of XPS to study the adsorption of salivary constituents on enamel has also been reported. ${ }^{13}$

\section{EXPERIMENTAL}

The conventional heat-compression mold technique was used to prepare acrylic resin test samples. The shallow half of a flask was filled with type IV dental stone (Duralit-S, Degussa A.G., Frankfurt, Germany) and its surface smoothed in order to achieve flat surfaces for the test samples. After a separating medium (Isolant, De Trey, London, U.K.) was applied to the stone surface, the upper half of the flask was filled with dental stone and the investment process completed. When the dental stone had set, the flask was opened and the separating medium applied to both dental stone surfaces. PMMA (Meliodent, Dental Bayer Limited Pharmaceuticals Div., Newburry, Berkshire, U.K.) was mixed according to the manufacturer's recommendations and cured by heat polymerization. The polymerized acrylic resin plaques were sectioned to small films with dimensions of $10 \times 15 \times 1$ $\mathrm{mm}$.

In a typical batch, 30 films prepared under same conditions were sectioned into three groups, the first of 
TABLE I. Contact-angle measurements of untreated (C) and plasma-treated PMMA left in air (A) and in distilled water (D).

\begin{tabular}{|c|c|c|c|c|c|c|c|}
\hline \multirow[b]{2}{*}{$\mathrm{C}$ (control) } & \multirow{2}{*}{$\begin{array}{c}0 \text { Days } \\
\text { A }\end{array}$} & \multicolumn{2}{|c|}{7 Days } & \multicolumn{2}{|c|}{14 Days } & \multicolumn{2}{|c|}{60 Days } \\
\hline & & $\mathrm{A}$ & $\mathrm{D}$ & A & $\mathrm{D}$ & A & $\mathrm{D}$ \\
\hline 51 & 54 & 53 & 48 & 46 & 42 & 53 & 45 \\
\hline 62 & 54 & 58 & 49 & 44 & 41 & 55 & 43 \\
\hline 61 & 51 & 48 & 49 & 47 & 44 & 54 & 48 \\
\hline 71 & 47 & 54 & 38 & 54 & 45 & 52 & 50 \\
\hline 70 & $\cdots$ & $\cdots$ & $\ldots$ & $\cdots$ & 46 & 42 & 37 \\
\hline 63 & 52 & 53 & 46 & 48 & 44 & 51 & 45 \\
\hline
\end{tabular}

which was used as control samples; the second and the third groups were subjected to plasma treatment. The second group was left exposed to laboratory atmosphere, and the third group was placed in distilled water right after plasma treatment until analysis. In some cases, the films were further subjected to in situ heating up to 100 ${ }^{\circ} \mathrm{C}$ or liquid $\mathrm{CH}_{2} \mathrm{Cl}_{2}$ for periods of $1-3 \mathrm{~min}$ before analysis.

Surface modification was achieved inside a tubular Pyrex ${ }^{\circledR}$ reactor, which could be evacuated and/or filled with various gases. Two copper electrodes on the Pyrex ${ }^{\circledR}$ reactor were capacitatively coupled to a radio-frequency (rf) plasma system consisting of a fixed-frequency (13.56-MHz) rf generator together with an rf power meter and a matching network. ${ }^{14}$ In this work, only the samples plasma-treated in evacuated reactor are reported. Since evacuation was achieved with a rotary pump only, the residual gases $(\sim 1-5$ Torr) consisting mostly of air and water vapor were expected to take active part in the plasma processes. Two different power settings (5 and $10 \mathrm{~W}$ ) for durations varying between $5 \mathrm{~min}$ to $1 \mathrm{~h}$ were applied.

Contact-angle measurements were carried out with the use of the entrapped air-bubble technique. ${ }^{15}$ FT-IR measurements were performed on a Bomem MD102 spectrometer with a Harrick DRA-B03 diffuse reflectance attachment. XPS measurements were performed on a Kratos ES300 spectrometer with $\mathrm{MgK} \alpha \mathrm{X}$-rays $(1253.6 \mathrm{eV})$ and a background pressure lower than $5 \times 10^{-9}$ Torr. All measurements and treatments were repeated at least three times to ensure reproducibility.

\section{RESULTS AND DISCUSSION}

Surface Modification. FT-IR measurements both in absorbance/transmittance or in reflectance mode could not detect any difference between the plasma-treated and untreated control samples, indicating that plasma treatment causes changes only in the very top layers. Contactangle measurements, with the use of the entrapped-air method, on the plasma-treated samples yielded values ranging between 48 and $54^{\circ}$, which were significantly lower than those of untreated control samples with an average value of $63^{\circ}$. Samples left in distilled water gave even lower values $\left(44-46^{\circ}\right)$. The results are summarized in Table I. Although several experiments using different power settings and/or durations were carried out, the values reported in this table are for one set of experimental conditions only ( $5 \mathrm{~W}$ and $10 \mathrm{~min}$ in duration).

XPS spectra recorded at $90^{\circ}$ and $30^{\circ}$ take-off angles of the control samples are given in Fig. 1. The general features are similar to the high-resolution spectra of PMMA

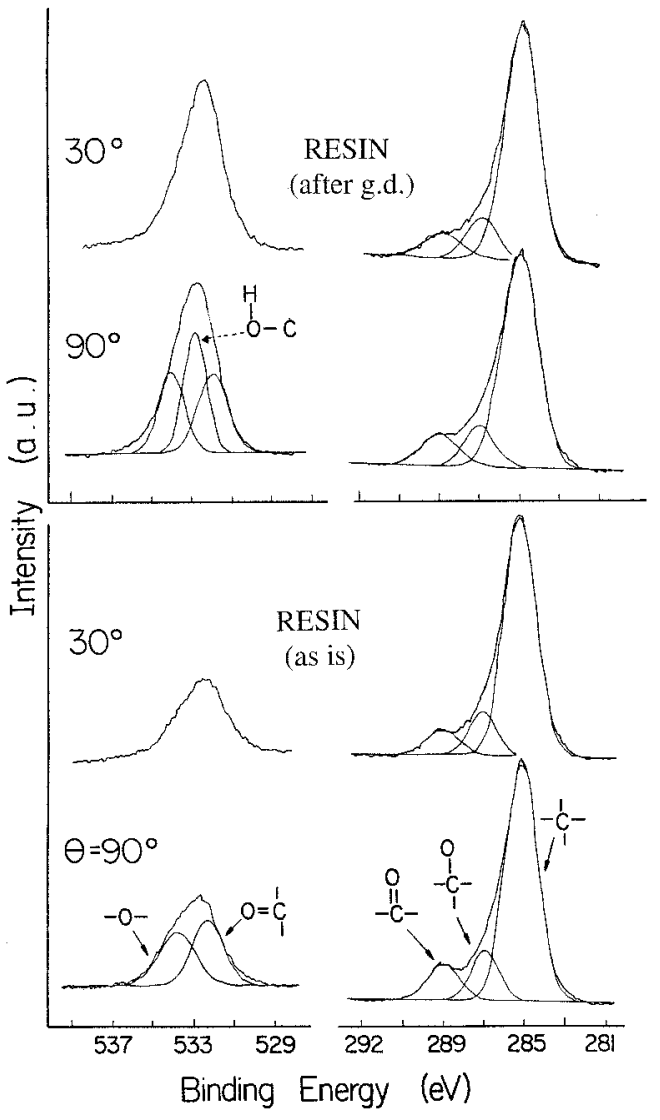

FIG. 1. O $1 \mathrm{~s}$ and C $1 \mathrm{~s}$ XPS of untreated PMMA at $90^{\circ}$ and $30^{\circ}$ takeoff angles and after treatment with glow discharge. The enhanced $\mathrm{O} 1 \mathrm{~s}$ signal is assigned to $-\mathrm{C}-\mathrm{OH}$.

compiled by Beamson and Briggs. ${ }^{11}$ Although the highresolution spectrum of Ref. 11 assigns four different carbons, we cannot resolve or can successfully differentiate between different hydrocarbon $\mathrm{C} 1 \mathrm{~s}$ peaks using curve fitting. Therefore, we fitted the $\mathrm{C} 1$ s region into only three peaks corresponding to $\mathrm{CH}, \mathrm{C}-\mathrm{O}$, and $\mathrm{C}=\mathrm{O}$ groups. The $\mathrm{O} 1 \mathrm{~s}$ region was fitted to two peaks corresponding to etheric and esteric oxygens. The main difference between our spectrum and that of pure PMMA reported by Ref. 11 is in the relative intensities of various $\mathrm{C} 1 \mathrm{~s}$ peaks and also $\mathrm{O} / \mathrm{C}$ atomic ratio. The $\mathrm{O} / \mathrm{C}$ atomic ratio in our control sample was 0.26 , which deviates from 0.40 in pure PMMA. Similarly in the $\mathrm{C} 1 \mathrm{~s}$ region, the ratio of both the etheric and esteric groups to total carbon intensity was around 0.14 , which is less than 0.20 expected from stoichiometry. The ratio of the sum of etheric and esteric $\mathrm{C}$ $1 \mathrm{~s}$ to total $\mathrm{O} 1 \mathrm{~s}$ intensity is very close to the stoichiometric ratio of 1.0. Therefore, the surface of our control samples seems to have additional $\mathrm{CH}$ groups, presumably stemming from the additives introduced through the various processes used in preparation and molding. There is no distinguishable difference between the spectra recorded at two different angles.

Spectra of the plasma-treated samples differ only in the $\mathrm{O} 1 \mathrm{~s}$ region with a narrower and more intense peak that can be curve fitted to three components. The extra peak in the $\mathrm{O} 1 \mathrm{~s}$ region at $533.0 \mathrm{eV}$ can be assigned to - $\mathrm{COH}$ groups, in agreement with Refs. 7-11 and 16-18. 
TABLE II. XPS measurements of untreated (C) and plasma-treated PMMA left in air (A) and in distilled water (D) for 14 days.

\begin{tabular}{|c|c|c|c|c|c|}
\hline & & \multirow[b]{2}{*}{$\mathrm{O}$ 1s } & \multicolumn{3}{|c|}{ C 1s } \\
\hline & & & $\mathrm{CH}$ & $\mathrm{C}-\mathrm{O}$ & $\mathrm{C}=\mathrm{O}$ \\
\hline $\begin{array}{l}\text { Resin } \\
\text { (C) }\end{array}$ & $\begin{array}{l}\text { B.E. }(\mathrm{eV})^{\mathrm{a}} \\
\text { Intensity }{ }^{\mathrm{b}} \text { at } 90^{\circ} \\
\text { at } 30^{\circ}\end{array}$ & $\begin{array}{l}532.5 \\
(0.26) \\
(0.27)\end{array}$ & $\begin{array}{l}285.0 \\
(0.73) \\
(0.74)\end{array}$ & $\begin{array}{l}286.7 \\
(0.14) \\
(0.14)\end{array}$ & $\begin{array}{l}288.9 \\
(0.14) \\
(0.13)\end{array}$ \\
\hline $\begin{array}{l}\text { Resin } \\
\text { (A) }\end{array}$ & $\begin{array}{l}\text { B.E. }(\mathrm{eV})^{\mathrm{a}} \\
\text { Intensity }{ }^{\mathrm{b}} \text { at } 90^{\circ} \\
\text { at } 30^{\circ}\end{array}$ & $\begin{array}{l}532.6 \\
(0.42) \\
(0.43)\end{array}$ & $\begin{array}{l}285.0 \\
(0.70) \\
(0.67)\end{array}$ & $\begin{array}{l}286.8 \\
(0.17) \\
(0.18)\end{array}$ & $\begin{array}{l}289.0 \\
(0.13) \\
(0.15)\end{array}$ \\
\hline $\begin{array}{l}\text { Resin } \\
\text { (D) }\end{array}$ & $\begin{array}{l}\text { B.E. }(\mathrm{eV})^{\mathrm{a}} \\
\text { Intensity } \text { at } 90^{\circ} \\
\text { at } 30^{\circ}\end{array}$ & $\begin{array}{l}532.6 \\
(0.34) \\
(0.35)\end{array}$ & $\begin{array}{l}285.0 \\
(0.70) \\
(0.69)\end{array}$ & $\begin{array}{l}286.8 \\
(0.15) \\
(0.15)\end{array}$ & $\begin{array}{l}288.8 \\
(0.15) \\
(0.16)\end{array}$ \\
\hline
\end{tabular}

${ }^{\mathrm{a}}$ B.E. = binding energy.

b Corrected for cross section and instrumental transmission function.

A small increase in the relative intensity of the $\mathrm{C}-\mathrm{O}$ component in the $\mathrm{C} 1 \mathrm{~s}$ region is also consistent with the above assignment. Differences in the angle dependence of various components are slightly more pronounced after plasma treatment. Relevant XPS data are collected in Table II.

One of the main characteristics of cold plasma treatment is the formation of radicals in high concentration on polymer substrate surfaces, the chemical structure and half-life of which are known to depend on the structure of the polymer and the plasma operational parameters. ${ }^{12,15}$ Besides the direct activation and functionalization with atomic oxygen of the gas phase, plasma radicals on the polymer surface can also react with molecular oxygen to form peroxides, which may lead to new species formation, such as hydroperoxides through hydrogen addition $\mathrm{R} \cdot+\mathrm{O}_{2}-\mathrm{ROO}-\mathrm{ROOH}$, which then can decompose to form stable species such as esters alcohols, depending on plasma conditions. ${ }^{12,17,18}$

XPS data together with contact-angle measurements clearly reveal that the increased wettability must be related to the chemical modification of the surface composition, especially to the increase in oxygen content. Since in XPS measurements one cannot detect hydrogen and can detect only relative changes in the surface composition, an increase in the oxygen content must be interpreted as relative to carbon. Second, since there is not a strong angular dependence, the modification is uniform up to several molecular layers into the bulk, greater at least than $5 \mathrm{~nm}$, which is typically the XPS sampling depth with the use of $\mathrm{MgK} \alpha$ radiation, ${ }^{11}$ but definitely less than $50 \mathrm{~nm}$, which is an overestimated sampling depth observable by FT-IR.

Heating in vacuum at $\sim 100{ }^{\circ} \mathrm{C}$ for $1-2$ min causes approximately a $15 \%$ reduction in the observed $\mathrm{O} / \mathrm{C}$ atomic ratio. Similarly, exposure of the plasma-treated samples to 1-2 min of liquid $\mathrm{CH}_{2} \mathrm{Cl}_{2}$ also decreases the $\mathrm{O} / \mathrm{C}$ atomic ratio by $20 \%$. The decrease in the $\mathrm{O} / \mathrm{C}$ atomic ratio as a result of (1) heating in vacuum, (2) exposure to $\mathrm{CH}_{2} \mathrm{Cl}_{2}$, or (3) exposure to distilled water can be explained by either $\mathrm{H}_{2} \mathrm{O}$ elimination (possibly by $-\mathrm{H}$ and -OH recombination) or surface reconstruction.

Durability of the Modification. To assess the durability of the plasma treatment, we followed up on the XPS O/C atomic ratios of the samples left in a laboratory environment $(\boldsymbol{A})$ and the ones placed in distilled water

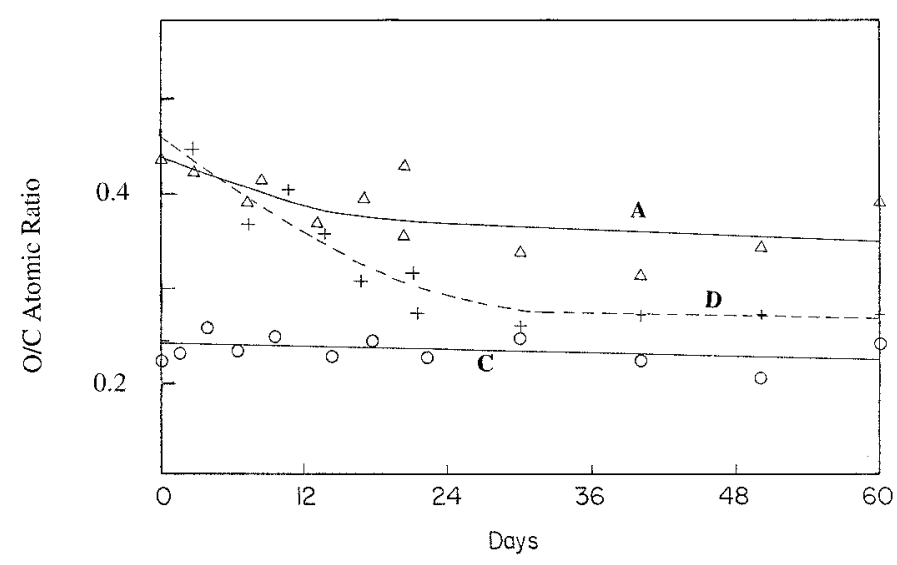

FIG. 2. Measured $\mathrm{O} / \mathrm{C}$ atomic ratios of plasma-treated samples left in a laboratory environment $(\boldsymbol{A})$ and placed in distilled water $(\boldsymbol{D})$ for a period of up to 60 days. Measurements in control samples not exposed to plasma $(\boldsymbol{C})$ are also included.

(D) for up to 60 days after plasma treatment (Fig. 2). Both in the samples left in air and those in distilled water, the $\mathrm{O} / \mathrm{C}$ atomic ratios decrease within the first two weeks but settle to 0.40 and 0.32 , respectively, up to 60 days for air and water samples, as compared to 0.26 for untreated control samples. The contact-angle measurements after 7,14 , and 60 days, however, reveal no significant changes for the same samples left in air or water. This difference must be attributed to the different probing capacities and/or sampling depths of the XPS and contactangle methods. However, both methods indicate a durable (at least up to 60 days) modification of the surfaces of the resin samples left in air or water, in contrast to Murray's in vitro findings. ${ }^{6}$ Differences between our results and those of Murray could be due to the different plasma treatments, which are known to be very strongly dependent on various experimental parameters. ${ }^{12,14,16,17}$

\section{CONCLUSION}

Glow-discharge plasma alters the surfaces of the acrylic resin and increases the wettability, as shown both by XPS and contact-angle measurements. The increased wettability can be attributed to the presence of $-\mathrm{COH}$ groups. Glow-discharge plasma treatment does seem to offer a durable (at least up to 60 days) wettability for these materials when left in air or distilled water.

1. A. W. Adamson, Physical Chemistry of Surfaces (Wiley, New York, 1990), 5th ed.

2. B. H. Z. Kilani, D. H. Retief, M. V. Guldag, D. J. Castleberry, and T. E. Fischer, J. Prosthet. Dent. 52, 288 (1984).

3. W. J. O'Brien and G. Ryge, J. Prosthet. Dent. 15, 304 (1965).

4. H. D. Gesser and C. R. Castaldi, J. Prosthet. Dent. 25, 236 (1971).

5. R. E. Lindstrom, J. Pawelchak, A. Heyd, and W. J. Tarbet, J. Prosthet. Dent. 42, 371 (1979).

6. M. D. Murray, J. Prosthet. Dent. 59, 368 (1988).

7. D. T. Clark and H. R. Thomas, J. Polm. Sci. Polm. Chem. Ed. 16, 791 (1978).

8. J. D. Andrade, R. R. King, and D. E. Gregonis, J. Colloid Interface Sci. 72, 488 (1979).

9. T. J. Hook, J. A. Gardella, Jr., and L. Salvati, Jr., J. Mater. Res. 2, 117 (1987).

10. E. M. Lehockey and I. Reid, Surf. Interface Anal. 11, 302 (1988).

11. G. Beamson and D. Briggs, High Resolution XPS of Organic Polymers (Wiley, New York, 1992). 
12. P. Gröning, O. M. Küttel, M. Collaud-Coen, G. Dietler, and L. Schlapbach, Appl. Surf. Sci. 89, 83 (1995).

13. Y. Kuboki, K. Teraoka, and S. Okada, J. Dent. Res. 66, 1016 (1987).

14. G. Akovali, J. Appl. Polym. Sci. 32, 4027 (1986).

15. A. N. Özden, P. Imirzalioğlu, and M. Mutlu, Tr. J. Med. Sci. 23, 43 (1995).
16. G. P. Lopez, D. G. Castner, and B. D. Ratner, Surf. Interface Anal. 16, 267 (1991).

17. B. Y. Qu, Y. H. Xu, W. F. Shi, and B. Ranby, Macromolecules 25, 5215 (1992).

18. A. G. Shard and J. P. Badyal, Macromolecules 25, 2053 (1992). 